\title{
Bulbocavernosus or anal reflex, one or both should be tested after spinal cord injury
}

\author{
Daniel E. Graves $\mathbb{D}^{1}$
}

Received: 5 December 2019 / Accepted: 9 December 2019

(c) International Spinal Cord Society 2020

\begin{abstract}
There are several methods for determining the remaining function of the sacral spinal cord following a spinal cord injury. Two of these methods are the bulbocavernosus and the anal wink reflexes. The choice of which reflex to use should be determined by the need for clinical information. These two reflexes provide similar information; however, they may have different prognostic value.
\end{abstract}

Here, we have two thoughtful and well-written papers, that for the most part agree. The job ahead of me is to describe the differences and provide some direction for the application of these reflexes. In these two papers "Anal Reflex Versus Bulbocavernosus Reflex in Evaluation of Patients with Spinal Cord Injury" [1] and "The sacral exam—what is needed to best care for our patients?" [2], the authors have many points of agreement. The fact that both reflexes provide information that can differentiate between upper motor neuron (UMN) and lower motor neuron (LMN) injuries. This seems to be the information of primary importance as it is a very important distinction for the future treatment and potential outcome of rehabilitation following spinal cord injury (SCI).

The fact that the anal reflex is contained within, yet not an official part of the International Standards for the Neurologic Classification of SCI (INSCSCI) is influential in the argument for its selection. However, it is not completely convincing due to the fact that the two reflexes may not be completely interchangeable. There is different information contained in the result of the two tests. The piece of the argument that is clearly missing is the actual agreement of the two reflexes. Given that the reliability of elicitation of the reflexes is not perfect, it seems that there could be a good deal of error if there was an official endorsement of a

Daniel E. Graves

Daniel.Graves@ Jefferson.edu

1 Thomas Jefferson University College of Rehabilitation Sciences, Philadelphia, PA, USA single reflex. For instance the bulbocavernosus reflex (BCR) may have predictive power for sphincter control and sexual function that is not present in the anal reflex [3]. However, the reliability of elicitation of the BCR is somewhat lower than the anal reflex.

The more concerning issue is the idea that the selection which reflex to test can be influenced by the comfort level of the clinician or the patient with touching parts of the body. This seems to be a somewhat specious argument since the proper method of elicitation of the reflexes involves penetration of the anus with a finger to feel the contraction. This has long been a point of contention in the administration of the INSCSCI [4]. There are at least three arguments to counter the discomfort issue. The primary issue is informed consent. Patients can easily be told the reason and method of elicitation of the reflex before it occurs. If the patient is informed concerning the reason for the examination, they can be free to object. In this case the clinician will have to base their examination on the information they have, without the BCR. A second issue is that the choice of testing a reflex should be based on the information necessary to answer a clinical question, not by social, cultural or religious mores. The third issue is that for the majority of cases the patient will have a catheter inserted and the BCR can be elicited by simply giving a slight tug on the tube, thereby eliminating the need to make contact with the patient other than the finger to detect the contraction.

In the end, the choice of which reflex to test will, and should, remain with the clinician. Perhaps the answer is to first test the reflex the clinician is most comfortable with, and then, if this is unable to be elicited, to test the other. If the purpose is simply to determine UMN versus LMN then 
either reflex would suffice. If the neurologic examination reveals a likelihood of the reflex being present (e.g., in the case of tetraplegia or high paraplegia, not related to a vascular injury, then perhaps the use of the anal wink would be appropriate as a first choice. Alternatively, in the situation of a cauda equina or conus injury, perhaps the BCR should be performed first. The choice should of course be driven by the need to obtain information to, as fully as possible and describe the clinical picture of the patient. The official designation of a single reflex limits the choice of tools available to a clinician as there are differences between the anal reflex and the BCR. To suggest that they are interchangeable gives a false sense of equivalence that may simply not be the case.

\section{Compliance with ethical standards}

Conflict of interest The author declares that they have no conflict of interest.
Publisher's note Springer Nature remains neutral with regard to jurisdictional claims in published maps and institutional affiliations.

\section{References}

1. Kirshblum S, Eren F. Anal reflex versus bulbocavernosus reflex in evaluation of patients with spinal cord injury. Spinal Cord Ser Cases. 2020. https://doi.org/10.1038/s41394-019-0251-3. [Epub ahead of print].

2. Previnaire JG, Alexander M. The sacral exam-what is needed to best care for our patients? Spinal Cord Ser Cases. 2020. https://doi. org/10.1038/s41394-019-0252-2. [Epub ahead of print].

3. Previnaire JG. The importance of the bulbocavernosus reflex. Spinal Cord Ser Cases. 2018;4:2.

4. Betz RB-SF, Burns SP, Donovan W, Graves DE, Guest J, Jones L, Kirshblum S, Krassioukov A, Mulcahey MJ, Schmidt Read M, Rodriguez GM, Rupp R, Schuld C, Tansey K, Walden K. The 2019 revision of the International Standards for Neurological Classification of Spinal Cord Injury (ISNCSCI)—what's new? Spinal Cord. 2019;57:815-7. 